\title{
One minute with the Metabolomics Society's Honorary Fellows 2015
}

Ute Roessner ${ }^{1}$, President

Timothy Ebbels ${ }^{2}$, Secretary

${ }^{1}$ School of BioSciences, The University of Melbourne, 3010 Victoria, Australia

${ }^{2}$ Computational \& Systems Medicine, Department of Surgery \& Cancer, Imperial College, South Kensington, London SW7 2AZ, UK.

At the beginning of this year the Metabolomics Society again asked for nominations for the award of Lifetime Honorary Fellows. Every year we elect two outstanding scientists and active members of our community and Society to recognize their contributions with this prestigious award. Important criteria for selection of awardees are their overall contribution to the metabolomics sciences in any area, e.g. in the development of novel technologies, application of metabolomics to advance a particular scientific issue, or for the development of computational tools for data analysis, interpretation or visualization. We are pleased to announce that the 2015 Honorary Fellows of the Metabolomics Society are Prof Robert Hall and Prof Mark Viant.

INSERT Picture Robert

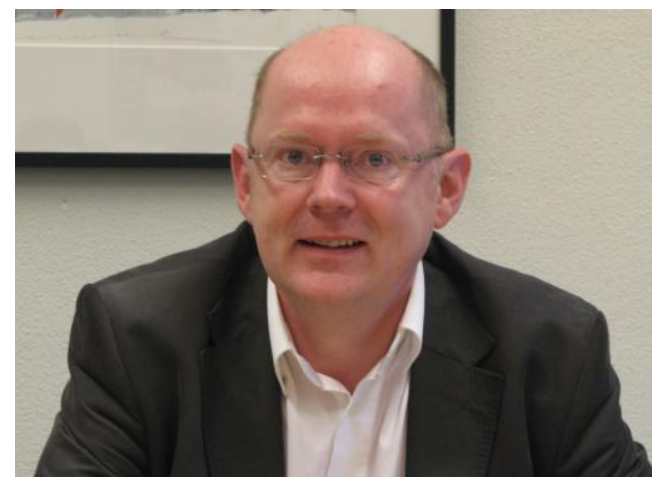

Professor Robert Hall: In recognition of his role as a founding pioneer and continuous champion for the use of Metabolomics as a powerful tool to improve our understanding of plant biochemistry, and as an acclaimed leader and servant to the Metabolomics community.

Robert has made outstanding service contributions to the Metabolomics Society as Secretary, President, and Director of the Board between 2008-2014. He has always provided thoughtful directions and intelligent advice that have been key to building and growing our Society. Robert is also a true pioneer of plant metabolomics. In fact, he and his colleagues at Plant Research International hosted the first international plant metabolomics conference in 2002. He has published over 160 papers on metabolomics technology, development and plant applications, including many 
excellent reviews in the early days to promote the technology. His accomplishments and contributions include being an Associate Editor of the Society's journal Metabolomics since its inception, and being a leading co-founder of the Netherland Metabolomics Centre, one of the first of its kind globally. He has edited two books on metabolomics, one on methodology and the other on potential applications of the technology. He has been awarded a personal Professorship in Plant Metabolomics at Wageningen University, he was the Co-Chair for the Metabolomics 2010 conference in Amsterdam and has served on Scientific Conference Organizing Committees of Metabolomics 2011 to 2014, and he was the coordinator of the EU project METAPHOR. In summary, Prof Hall is a founding pioneer and continuous champion for the use of Metabolomics as a powerful tool to better understand plant biochemistry, and he is an acclaimed leader and Ambassador to the Metabolomics community.

INSERT Picture Mark

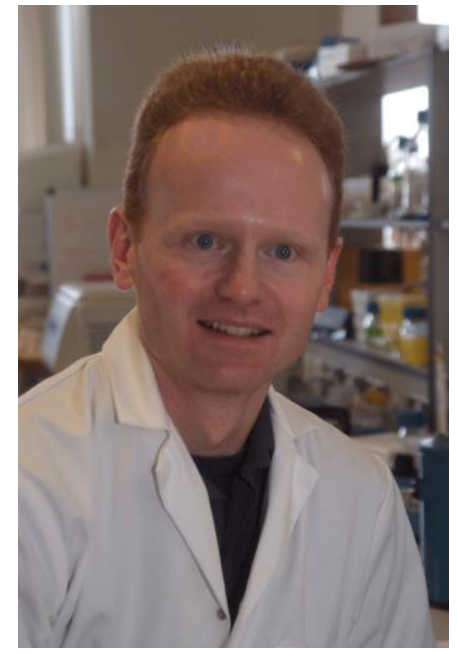

Professor Mark Viant: In recognition of his pioneering work in environmental metabolomics and for his sustained service to the Society. His vision revolutionized the Society's operations and reputation, expanding its reach to all corners of the world.

Prof Viant is an international leader in metabolomics with a particular emphasis on environmental metabolomics. He can be considered as one of the pioneers utilizing metabolomics approaches to solve environmental problems. His scientific track record is excellent with 124 peer-reviewed publications, 6 book chapters and grants totaling well over $£ 10 \mathrm{M}$ as PI or Co-PI. Prof Viant has been involved with the Metabolomics Society for many years but has been particularly important for the Society's reputation and growth when he was elected as President in 2012. Prof Viant committed his boundless energy and time to Society business, establishing many new initiatives, which are now a characteristic of the Society. He was able to increase 
member involvement by establishing a new type of Society grouping, the task group, which involve both board and non-board members working together to solve a pressing issue in the field. This has greatly extended the breadth and richness of interactions within the Society. His contributions have come in many areas to: (1) metabolomics as a science in environmental sciences, (2) the development of analytical advancements in both NMR and MS applications, (3) the development of sophisticated software tools for data analysis and (4) the growth and development of the Society. His continuous enthusiasm and support for our Society and his wider impact promoting metabolomics as a science warrants Prof. Viant being elected as an Honorary Fellow of the Metabolomics Society.

We have taken the opportunity of their election to ask Profs Hall and Viant some unusual questions. Many of us in the community will know the scientific and Societal activities and outputs of the Honorary Fellows, but we may know less about what motivates them and their life outside science. Below are one minute interviews with both:

\section{Prof Robert Hall}

\section{What do you enjoy most about your job?}

I love that we are working with a new approach to look at a component of living organisms which has huge importance and which has really broad relevance. In plants the biochemical composition determines not only the quality of our food, how to produce bioactives etc. but also how a plant is armoured to survive in a hostile environment and propagate successfully. Metabolomics is very much a multidisciplinary science, which has brought different disciplines together in ways not happening before. It is a real team - based science.

\section{What might people be surprised to hear about you?}

Perhaps that all my main hobbies are not scientific but cultural - I spend a lot of my free time attending art exhibitions and visiting theatre productions but perhaps my main hobby is anything art deco as my whole house is furnished with art deco artefacts which I collect from all over the world.

\section{If you weren't doing this, what might you be doing instead?}

I would probably have been a medical doctor - I actually studied medicine for a month (!) before deciding that plants were my only true love!

Prof Mark Viant's answers:

1. What do you enjoy most about your job?

I thoroughly enjoy the teamwork. Leading a multi-national, multi-cultural research group that is harmonised and focused on a shared vision to develop metabolomics sciences and in particular to transform the way we assess and regulate human and environmental health is truly exciting. I also thoroughly enjoy mentoring early career 
researchers to their full potential and guiding them towards an independent academia career.

2. What might people be surprised to hear about you?

I'm an avid plane fanatic, and love attending air shows (especially with my two boys). There is nothing more enjoyable than listening to the purr of a Rolls Royce Merlin engine as a Spitfire makes a low pass over the airfield and climbs into a deep blue sky.

\section{If you weren't doing this, what might you be doing instead?}

It's hard for me to imagine ever being too far from science. If it wasn't metabolomics then the forensic sciences appeal a lot, developing new diagnostic methods. If I had to leave science, and since I am now too old to be a Spitfire pilot, my next choice would be a professional gardener (biology in action!). 


\section{University Library}

\section{- M M I E R R A A gateway to Melbourne's research publications}

Minerva Access is the Institutional Repository of The University of Melbourne

Author/s:

Roessner, U;Ebbels, T

Title:

One minute with the Metabolomics Society's Honorary Fellows 2015

Date:

2015-08-01

Citation:

Roessner, U. \& Ebbels, T. (2015). One minute with the Metabolomics Society's

Honorary Fellows 2015. METABOLOMICS, 11 (4), pp.779-781. https://doi.org/10.1007/ s11306-015-0820-9.

Persistent Link:

http://hdl.handle.net/11343/282841 